\title{
ANALISIS VISUAL ILUSTRASI SAMPUL NOVEL FIVE FEET APART BERDASARKAN PRINSIP-PRINSIP DESAIN
}

\author{
Aulia Chairunissa ${ }^{1}$, Shanti Mustika ${ }^{2}$, Umairoh $^{3}$ \\ Program Studi Desain Komunikasi Visual, \\ Fakultas Bahasa Dan Seni, Universitas Indraprasta PGRI \\ Jl. Nangka 58 C Tanjung Barat, Jakarta Selatan, 12530, Indonesia \\ Email: auliachairunissal@gmail.com
}

\begin{abstract}
Abstrak
Tujuan penelitian ini adalah untuk menganalisis unsur-unsur visual yang terkandung pada ilustrasi sampul novel Five Feet Apart dan mendeskripsikan setiap unsur yang terkandung di dalam ilustrasi sampul tersebut yaitu bentuk, warna dan tipografi. Penelitian ini merupakan penelitian deskriptif kualitatif, objek penelitiannya adalah sampul novel Five Feet Apart. Penelitian ini difokuskan pada ilustrasi sampul novel secara keseluruhan yaitu sampul bagian depan yang terdiri dari bentuk ilustrasi, warna dan tipografi. Data yang diperoleh dianalisis secara deskriptif kualitatif dengan mendeskripsikan unsur-unsur visual yang ada kaitannya dengan isi cerita novel. Kegiatan analisis data dimulai dari tahap identifikasi dan klasifikasi data, kemudian pembahasan data, dan verifikasi data. Hasil penelitian menunjukan bahwa ilustrasi sampul novel mengandung unsur-unsur visual, seperti bentuk, warna dan tipografi untuk mengomunikasikan pesan cerita novel yang berupa warna latar biru tua dan merah muda, paru-paru, pohon ranting, bunga tulip, siluet orang, dan gradasi warna lain terhadap warna ilustrasi sampul. Sementara tipografi pada ilustrasi sampul memberikan penegasan mengenai sesuatu yang tidak bahagia atau bermakna kesedihan pada cerita novel. Keseluruhan unsurunsur visual ilustrasi sampul saling terkait dalam membentuk pesan utama cerita novel yang dapat memicu rasa ingin tahu khalayak untuk membacanya.
\end{abstract}

Kata Kunci: Visual, Novel, Ilustrasi, Sampul, Five Feet Apart

\begin{abstract}
The purpose of this study was to analyze the visual elements contained in the cover illustrations of the novel Five Feet Apart and describe each element contained in the sampul illustrations, namely shape, color and typography. This research is a qualitative descriptive study, the object of the research is the cover of the novel Five Feet Apart. This research is focused on the illustration of the overall cover of the novel that is the front cover consisting of illustrations, colors and typography. The data obtained were analyzed descriptively qualitatively by describing the visual elements that exist with relation to the contents of the novel's story. Data analysis activities start from the identification and classification of data then discussion of data and data verification. The results showed that the novel cover illustration contained visual elements contained in the novel cover illustration, namely shape, color and typography in communicating novel story messages in the form of dark blue and pink background, lungs, twigs, tulips, silhouettes people, and other color gradations against the color of the cover illustration. While typography in the sampul illustration affirms something that is unhappy or sad means the story of the novel. So that all the visual elements of the cover illustration are interrelated in forming the main message of the novel's story that can trigger the curiosity of the audience to read it.
\end{abstract}

Keywords: Visuals, Novels, Illustrations, Covers, Five Feet Apart

Correspondence author: Aulia Chairunissa, auliachairunissa1@gmail.com, Jakarta, and Indonesia 


\section{PENDAHULUAN}

Semakin berkembangnya teknologi komunikasi di era globalisasi saat ini memberikan dampak kepada dunia seni rupa. Banyaknya elemen media yang menggunakan ilustrasi sebagai penarik perhatian utama bagi siapapun yang melihatnya, seperti halnya membaca. Membaca tidak bisa dipisahkan dari kebutuhan setiap manusia. Terutama generasi muda di Indonesia yang masih kurang memiliki minat untuk membaca. Hal ini disebabkan oleh berbagai macam faktor seperti, kejenuhan saat membaca dengan desain tulisan yang membosankan, kurangnya daya imajinasi, dan lain lain.

Salah satu cara menarik minat pembaca adalah dengan sebuah desain ilustrasi sampul buku. Menurut kamus, yang dimaksud ilustrasi adalah gambar, diagram, atau peta yang digunakan untuk menjelaskan atau menghias sesuatu. Hiasan tersebut bisa berupa kata (tekstual), bisa juga gambar. Menurut Dwi Koendara dalam (Maharsi, 2016) konteks hiasan berarti kata-kata yang terbaca maupun gambar yang divisualkan akan memberikan kesan atau menimbulkan nilai-nilai estesis dan menjadi indah. Terlihat konteks ilustrasi lebih kepada bahasa yang estesis, lebih merujuk kepada kata maupun gambar yang enak atau sedap dipandang. Desain ilustrasi sampul buku menjadikan pembaca tertarik untuk membaca sekaligus berfungsi sebagai bahasa iklan. Sampul yang menarik menimbulkan rasa ingin tahu para calon pembaca yang mencari sebuah bacaan yang menarik dan tidak membosankan.

Desain adalah aktivitas personal dan tumbuh dari dorongan kreatif seorang individu (Hans, 2010). Dalam membuat sebuah karya desain seorang desainer harus melakukan riset terlebih dahulu. Dalam perancangan sampul, desain harus disesuaikan dengan isi cerita dari novel. Hal tersebut membuat desain sampul yang dibuat memiliki makna yang berhubungan dengan isi dari novel tersebut. Makna yang terdapat dalam sampul novel dapat diuraikan melalui elemen-elemen visual yang muncul pada sampul. Selain itu harus menerapkan prinsipprinsip desain.

Dalam prinsip-prinsip desain terdapat keseimbangan (balance). Keseimbangan adalah keseluruhan komponen-komponen desain harus seimbang. Ada dua jenis penerapkan keseimbangan, yaitu keseimbangan simetris dan asimetris. Keseimbangan simetris berdasarkan pengukuran keseimbangan ke arah sisi kanan dan kiri. Sedangkan asimetris berarti pengaturan yang berbeda dengan berat benda yang sama di setiap desain.

Selanjutnya kesatuan (unity) kesatuan dalam prinsip desain grafis adalah kohesi, konsistensi, ketunggalan atau keutuhan, yang merupakan isi pokok dari komposisi. Dengan prinsip kesatuan dapat membantu semua elemen menjadi sebuah kepaduan dan menghasilkan tema yang kuat. Selain itu juga harus menerapkan ritme (rhythm). Ritme yang diartikan pembuatan desain dengan prinsip yang menyatukan irama dapat juga di artikan sebagai pengulangan atau variasi dari komponen-komponen desain grafis.

Dalam prinsip-prinsip desain juga terdapat penekanan (emphasis), dalam setiap desain ada hal yang perlu mendominasi lebih dari yang lain. Tujuan utama dari penekanan ini mengarahkan pandangan khalayak sehingga pesan yang disampaikan dapat tersalur dengan baik. Selain itu Hubungan perbandingan antara bagian dengan bagian lain atau bagian dengan elemen keseluruhan. Dapat juga diartikan sebagai perubuhan ukuran/size tanpa perubahan ukuran panjang, lebar, atau tinggi, sehingga gambar dengan perubahan proporsi sering terlihat distorsi atau yang disebut proporsi.

Dalam sebuah sampul terdapat berbagai macam elemen-elemen penunjang yang termuat didalamnya seperti desain ilustrasi, typography, serta warna. Sampul sendiri merupakan sebuah sampul buku yang menutupi serta melindungi buku dan sekaligus sebagai bahasa visual yang mengekpresikan isi buku. Sampul buku memiliki beberapa unsur yang dapat dijelaskan dan dianalisa. Kami akan membahas salah satu sampul novel berjudul "Five Feet Apart" untuk mencari makna yang terkandung dan prinsip-prinsip desain didalam ilusrasi sampul tersebut.

Pentingnya sebuah ilustrasi sampul adalah untuk menarik minat baca dan menggambarkan secara ringkas isi bacaan, hal tersebut mendorong kami untuk meneliti secara dalam tentang ilustrasi sampul novel Five Feet Apart yang merupakan novel yang mengangkat penyakit Cystic Fibrosis dan sukses diangkat ke dalam film. Kami ingin meneliti bagaimana 
keterkaitan ilustrasi sampul dengan isi cerita dan apa sajakah unsur-unsur visual yang terdapat pada ilustrasi sampul novel tersebut dilihat dari bentuk ilustrasi, warna dan tipografi, apakah sudah menarik sehingga sesuai dengan julukan novel tersebut yang best seller dan prinsipprinsip desain yang terdapat pada sampul novel Five Feet Apart.

Berdasarkan data diatas terciptalah suatu rumusan masalah mengenai bagaimana visualisasi desain sampul novel tersebut serta bagaimana prinsip-prinsip desain dan makna dalam visualisasi desain sampul novel tersebut. Tujuan dari permasalahan yang muncul yaitu mendeskripsikan visualisai desain sampul novel Five Feet Apart serta mengetahui prinsip prinsip desain dan makna visualisasi desain sampul novel tersebut.

\section{METODE PENELITIAN}

Penelitian ini menggunakan metode penelitian kualitatif yang bersifat deskriptif. Menurut Bogden dan Taylor (dalam Moleong, 2007), metedologi kualitatif sebagai prosedur penelitian yang menghasilkan data deskriptif berupa kata-kata tertulis atau lisan dari orang orang atau perilaku yang dapat diamati. Dalam analisis tersebut peneliti menggunakan metode ini agar peneliti dapat menemukan informasi dan berita secara umum dari situs resmi. Penelitian ini menggunakan analisis prinsip-prinsip desain dengan menganalisis ilustrasi yang terdapat pada sampul novel "Five Feet Apart". Pengumpulan data dilakukan dengan studi dokumentasi, mengambil dari situs resmi. Instrumen yang digunakan untuk mengumpulkan data berupa instrumen manusia, yaitu peneliti sendiri. Untuk menjaga keabsahan data, dilakukan triangulasi data. Kegiatan analisis data dimulai dari tahap identifikasi dan klasifikasi data kemudian pembahasan data dan verifikasi data.

Peneliti berharap dengan adanya artikel ini pembaca dapat memahami cara membuat desain yang sesuai dengan prinsip-prinsip desain dan memiliki makna disetiap desain yang di buat.

\section{HASIL DAN PEMBAHASAN}

Novel Five Feet Apart yang ditulis oleh Rachael Lippincott, Mikki Daughtry, dan Tobias Iaconis yang diterbitkan pada tahun 2018 dengan isi buku 288 halaman. Novel Five Feet Apart menceritakan kisah cinta Stella Grant (Haley Lu Richardson) merupakan gadis berusia 17 tahun dan Will Newman (Cole Sprouse) dengan penyakit langka, Cystic Fibrosis.

Cystic Fibrosis adalah penyakit keturunan yang mempengaruhi paru-paru dan sistem pencernaan. Tubuh menghasilkan lendir kental dan lengket yang dapat menyumbat paru-paru dan menyumbat pankreas. Cystic Fibrosis dapat mengancam jiwa, dan orang-orang dengan penyakit ini cenderung memiliki rentang hidup yang lebih pendek dari normal. Saat ini tidak ada obat untuk penyakit Cystic Fibrosis, tetapi nutrisi yang baik dan mengambil langkahlangkah untuk mengencerkan lendir dapat membantu. Cystic Fibrosis merupakan penyakit langka saat ini kurang dari 150 ribu kasus pertahun di Indonesia.

Novel Five Feet Apart menceritakan tentang Stella dan Will yang hidup dengan gangguan genetik, keduanya berusaha menemukan kesamaan, bertemu, dan saling jatuh cinta. Pengidap penyakit Cystic Fibrosis harus membawa tabung oksigen dan masker khusus ke manapun. Larangan untuk saling kontak secara fisik menjadi hambatan tersendiri bagi Stella dan Will (Dayana, 2019).

Stella Grant memilliki paru-paru yang tidak terkendali yang membuat hampir sepanjang hidupnya keluar masuk rumah sakit. Pada titik ini, apa yang paling perlu dikendalikan Stella adalah menjauhkan diri dari siapa pun atau apa pun yang mungkin dapat menularkan infeksi dan membahayakan kemungkinan transplantasi paru-paru. Memberi jarak terpisah lima langkah tidak ada pengecualian (Agnes, 2019).

Satu-satunya hal yang ingin dikontrol oleh Will adalah keluar dari rumah sakit. Will tidak peduli tentang perawatannya, atau uji coba obat klinis baru yang mewah. Will akan berusia delapan belas tahun dan kemudian dia akan bisa mencabut semua mesin ini dan benarbenar pergi melihat dunia, bukan hanya rumah sakitnya. Will akan persis seperti Stella yaitu harus menjauhkan diri dari siapa pun atau apa pun yang mungkin dapat menularkan infeksi. Jika 
mereka tidak memberi jarak satu sama lain salah satu dari mereka bisa mati. Satu-satunya cara untuk tetap hidup adalah dengan tetap terpisah. Tapi tiba-tiba lima langkah tidak terasa seperti aman rasanya seperti hukuman.

\section{Visualisasi Desain Sampul Novel Five Feet Apart}

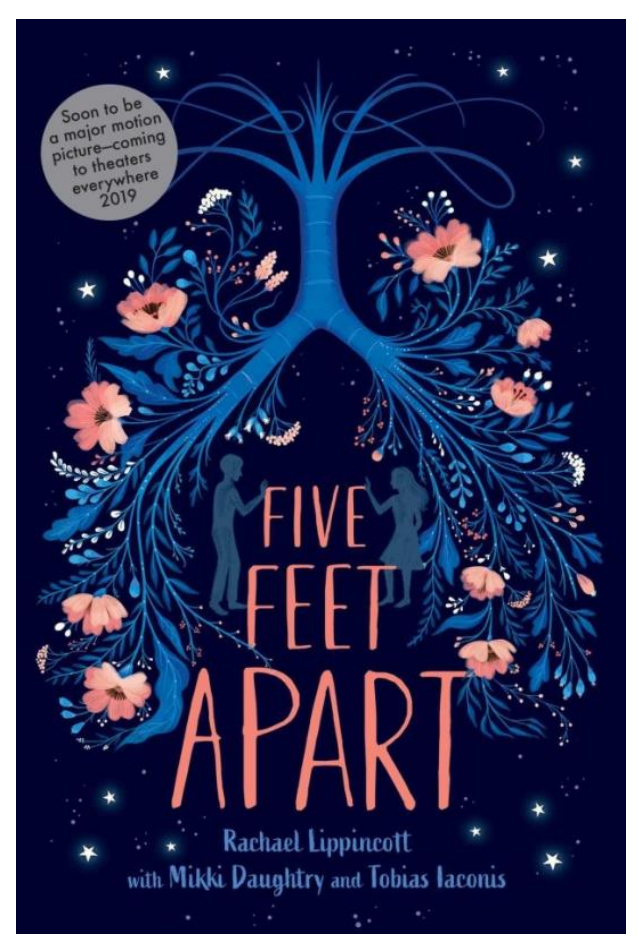

Gambar 1 Desain Sampul Novel Five Feet Apart

Sumber: pinterest/casualoptimist.com

Judul utama pada desain sampul Five Feet Apart menggunakan jenis font San-Serif. Font San-Serif ini merupakan kebalikan dari font Serif hanya saja bedanya jika font Serif memiliki sepatu, kait atau mata pancing, maka font San-Serif tidak memiliknya (Mahesa, 2019). Jenis font San-Serif berasal dari kata sendiri memiliki arti tanpa atau tidak. Desain dari jenis font San-Serif terlihat standar, sehingga memberikan kesan netral kepada pembaca. Font ini juga memiliki sifat yang tegas dan modern, sangat cocok digunakan pada sebuah judul dari sampul novel tersebut. Dengan mengedepankan unsur modern meningkatkan minat masyarakat dalam membaca dikarenakan masyarakat lebih menyukai sesuatu yang unik dan berwarna dibanding hal yang monoton. Warna yang digunakan pada judul novel Five Feet Apart menggunakan warna yang berbeda dari warna yang mendominasi sampul tersebut. Warna yang terlihat terkesan lebih cerah dibanding seluruh warna sampul yang mendominasinya, ragam warna bisa menimbulkan efek psikologis yang kuat. Ketika kita melihat warna, sistem syaraf pada otak akan merespon dan menyebabkan kelenjar hypothalamus melepaskan hormonhormon tertentu. Warna cerah yang tampil pada sampul buku bernuansa merah muda atau pink yang memiliki makna aura yang kuat serta memberikan nuansa kelemahlembutan, peduli, dan romansa. Selain makna dari pemilihan warna, font judul juga memiliki tujuan agar pembaca tertuju pada judul dari novel tersebut. 


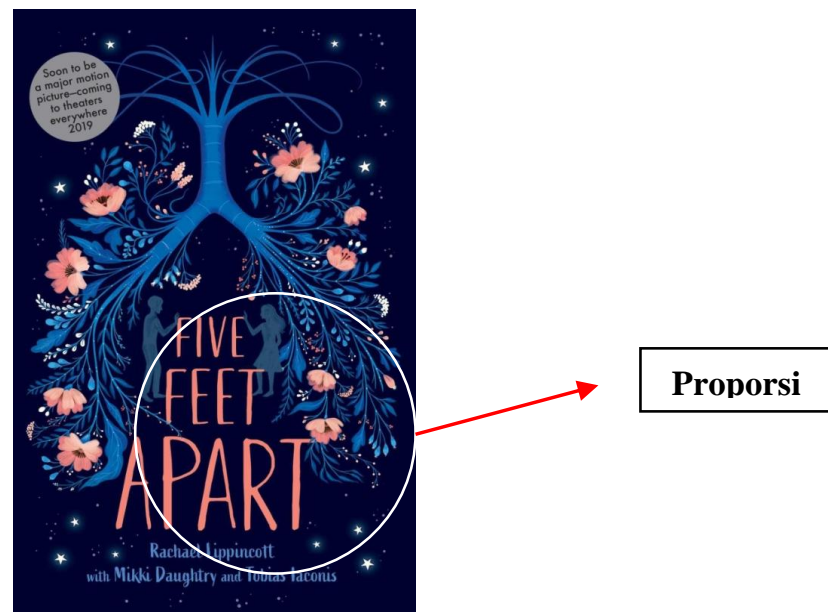

Gambar 2 Analisis Proporsi

Sumber: pinterest/casualoptimist.com

\section{Proporsi}

Selain itu pada teks judul Five Feet Apart terdapat prinsip desain yaitu proporsi, Proporsi sendiri dapat diartikan sebagai perubahan ukuran/size tanpa perubahan ukuran panjang, lebar, atau tinggi, sehingga gambar dengan perubahan proporsi sering terlihat distorsi. Dari novel tersebut terlihat ada perubahan ukuran teks dari judul novel Five Feet Apart yang ukuranya semakin membesar.
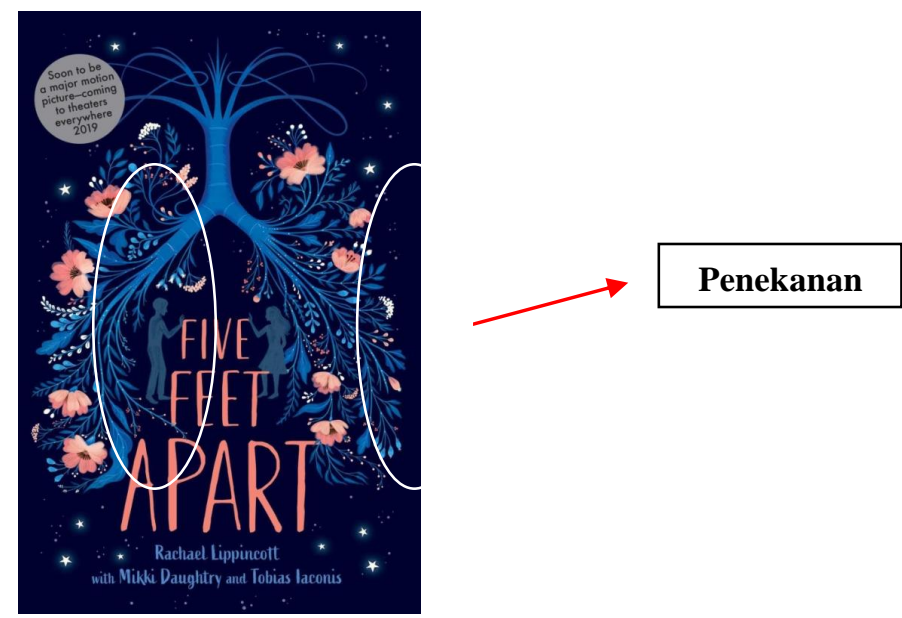

Gambar 3 Analisis Penekakanan

Sumber: pinterest/casualoptimist.com

\section{Penekanan (emphasis)}

Pada sampul novel Five Feet Apart didominasi oleh ilustrasi. Terdapat ilustrasi paruparu yang menjadi point of interest dari desain sampul tersebut. Terdapat penerapan prinsip desain berupa emphasis atau tekanan karena penonjolan salah satu unsur yaitu pada gambar ilustrasi paru-paru. 


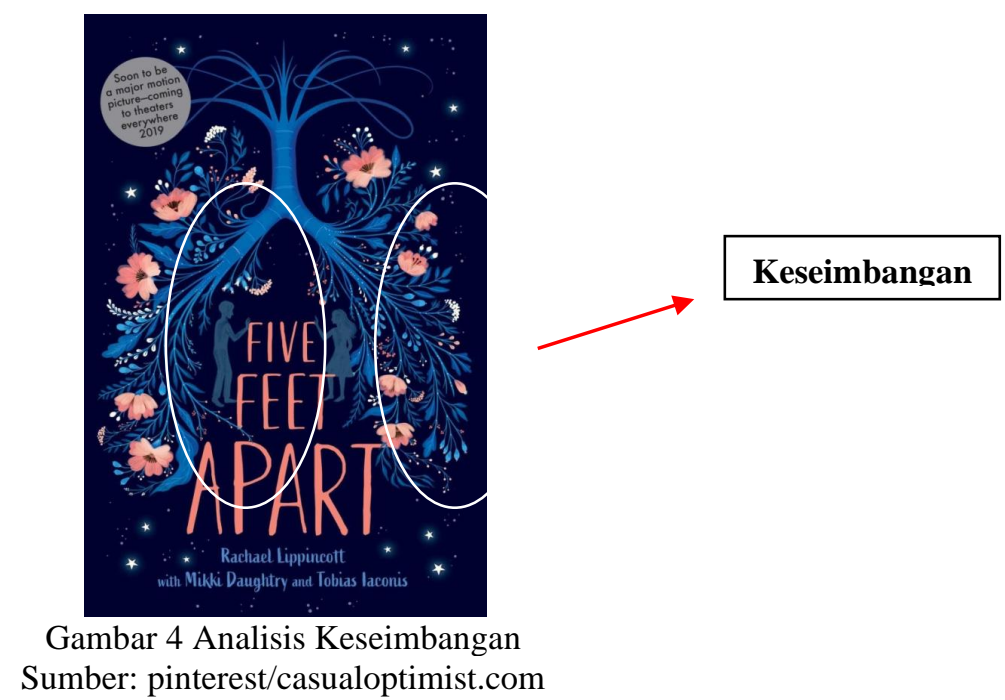

\section{Keseimbangan (balance)}

Dalam desian sampul novel Five Feet Apart juga terdapat prinsip desain yang diterapkan pada sampul novel ini adalah keseimbangan simetris yaitu terdapat pada gambar paru-paru dan gambar dua orang. Warna yang mendominasi sampul novel ini yakni biru tua dan merah muda. Warna merah muda diterapkan pada teks judul sedangkan, warna biru tua digunakan pada background. Terdapat pula irama berupa variasi, yakni pengulangan bintang pada background dengan variasi bentuk dan posisi.

\section{Kesatuan (unity)}

Penerapan prinsip desain kesatuan terlihat pada warna, tipografi, dan ilustrasi. Ketiga unsur ini membuat sampul novel menjadi utuh. Hal ini karena tipografi dengan jenis font SanSerif memberi kesan netral, diperkuat juga dengan ilustrasi yang baik dan warna yang senada dengan warna ilustrasi yang ditampilkan.

\section{Makna Desain Sampul Novel "Five Feet Apart"}

Dalam desain sampul novel "Five Feet Apart" terdapat ilustrasi paru-paru yang memiliki makna penyakit yang diderita oleh kedua remaja yang ada dalam cerita novel tersebut. Penyakit yang diderita oleh kedua remaja tersebut adalah Cystic Fibrosis yang merupakan penyakit keturunan yang memengaruhi paru-paru. Ilustrasi paru-paru yang tergambar bukan sebuah paru-paru sebenarnya melainkan pohon dengan ranting yang menjuntai ke bagian kiri dan kanan. Ranting pohon tersebut tidak kokoh dan terkadang patah, namun ia mampu untuk menahan beban apapun yang menempel pada dirinya. Dibalik ranting-rantingnya yang mudah patah, tetapi ranting ini masih bisa dimanfaatkan. Karena setiap hal apapun yang mudah patah tak selamanya tak berguna selama kita bisa memanfaatkannya dengan baik. Sama halnya seperti cerita dalam novel tersebut kedua tokoh yang memiliki penyakit mematikan dan langka samasama tetap berjuang untuk sembuh selama belasan tahun, walaupun paru-paru mereka mengidap penyakit Cystic Fibrosis tetapi dengan bantuan dokter dan alat media mereka tetap bisa hidup dan berjuang.

Di sekeliling ilustrasi paru-paru terdapat ilustrasi bunga yang amat cantik dan indah. Bunga tersebut memiliki warna amat cerah berbeda dengan seluruh ilustrasi yang terkesan gelap. Bunga tersebut memiliki dua sisi warna yang terkesan gradasi yaitu putih dan orange. Terlihat bunga pada ilutrasi seperti bunga tulip yang merupakan pelambangan dari dekralasi rasa cinta. Warna orange pada ilustrasi bunga mengandung kebahagiaan dan suka cita. Hal yang tertangkap melalui ilustrasi tersebut meskipun dua orang terpisahkan dalam jarak 5 langkah tetapi mereka tidak menyesal bertemu satu sama lain dan merasakan cinta. 
Dari segi warna background buku ilustrasi tersebut sang desainer memilih warna gelap biru tua yang menjorok ke warna hitam, hal ini melambangkan sesuatu yang tidak bahagia atau bermakna kesedihan. Memang isi dari novel tersebut terbilang memberi efek kesedihan atas penyakit yang diderita oleh kedua pasangan yang saling mencintai tetapi tidak bisa bersentuhan secara fisik.

Di tengah gambar ilustrasi paru-paru, di sebelah kanan dan kiri terdapat ilustrasi dua orang yaitu laki-laki dan perempuan yang dipisahkan oleh teks yang memiliki makna bahwa kedua remaja memberi jarak terpisah lima langkah yang merupakan jarak aman dan apabila mereka tidak memberi jarak satu sama lain, salah satu dari mereka bisa mati.

Pada judul utama pada desain sampul yaitu Five Feet Apart yang berarti terpisah lima kaki, yang memiliki makna bahwa kedua remaja tersebut dengan penyakit yang dideritanya yaitu Cystic Fibrosis mengharuskan menjauhkan diri dari siapa pun atau apa pun yang mungkin dapat menularkan infeksi dan membahayakan kemungkinan transplantasi paru-paru yaitu dengan memberi jarak lima langkah.

Pada sekeliling gambar ilustrasi terdapat cahaya cerah berwarna putih yang terlihat seperti bintang bintang yang mengelilingi ilustrasi. Bintang tersebut tersebar ke berbagai titik dan terlihat sangat indah. Bintang sendiri memiliki makna menyenangkan, jujur, ikhlas, dan menerima. Ketika gulita mulai datang, bintang bersinar terang, hingga kerlipnya terlihat indah untuk dipandang. Ketika matahari tiba, bintang masih setia membagi sinarnya, meski dia tau kerlipnya tak seberapa jika dibandingkan dengan cahaya sang surya. Ketika mendung mulai menyelimuti tubuh mungilnya. Dia masih saja bersikukuh untuk tetap berpijar, meski terangnya hanya samar-samar. Tak peduli, tak ada satupun makhluk bumi yang bisa melihatnya berselimut mega, tak peduli tak ada seorang pun yang memuji kerlip indahnya, dia tetap mencoba untuk selalu bercahaya. Bintang tersebut memiliki makna dari terciptanya ilustrasi sampul buku Fife Feet Apart. Novel ini berusaha menceritakan roman remaja yang sama-sama memiliki waktu hidup yang terbatas karena penyakit yang mereka derita. Mengidap sebuah penyakit yang membuat seseorang mudah terinfeksi tentunya memberikan tantangan besar di kehidupannya sehari-hari. Makna bintang yang menyenangkan, jujur, dan indah, merepresentasikan setiap adegan atau cerita yang tertuang dalam novel ini. Meskipun kedua remaja memiliki penyakit yang mematikan tetapi dengan dipertemukanya Will dan Stella adalah sebuah kebahagian yang terpancar dari keduanya. Makna lain yang bisa kita ambil dari sebuah bintang adalah harapan. Banyak cerita yang menafsirkan sebuah bintang atau bintang jatuh memiliki arti harapan, sehingga orang dapat membuat sebuah harapan yang diinginkan dan berharap hal tersebut menjadi nyata ketika melihat bintang jatuh. Sama seperti novel ini ketika Stella selalu berharap dan terus menyemangati Will untuk mau menjadi kelinci percobaan atas obatnya yang sudah ditemukan. Hal tersebut agar Will bisa sembuh dan hidup normal disusul oleh Stella.

\section{SIMPULAN}

Analisis visual ilustrasi sampul novel Five Feet Apart bertujuan untuk mendeskripsikan makna-makna yang terkandung dalam unsur-unsur visual ilustrasi secara jelas. Penggunaan bentuk, warna dan tipografi pada ilustrasi novel saling berkaitan satu sama lain dan berhubungan erat dengan cerita tersebut. Unsur dari novel tersebut menggambarkan tentang dua remaja dengan penyakit yang dideritanya yaitu Cystic Fibrosis. Penyakit ini mengharuskan mereka menjauhkan diri dari siapa pun atau apa pun yang mungkin dapat menularkan infeksi dan membahayakan kemungkinan transplantasi paru-paru, yaitu dengan memberi jarak lima langkah. Digambarkan dengan jelas pada ilustrasi paru-paru yang memiliki makna pohon dengan ranting yang menjuntai ke bagian kiri dan kanan. Ranting pohon tersebut tidak kokoh dan terkadang ia patah, namun ia mampu untuk menahan beban apapun yang menempel pada dirinya. Dibalik ranting-rantingnya yang mudah patah, tetapi ranting ini masih bisa dimanfaatkan. Karena setiap hal apapun yang mudah patah tak selamanya tak berguna selama kita bisa memanfaatkannya dengan baik. Sama halnya seperti cerita dalam novel tersebut kedua tokoh yang memiliki penyakit mematikan dan langka sama-sama tetap berjuang untuk sembuh 
selama belasan tahun. Meskipun paru-paru mereka mengidap penyakit Cystic Fibrosis, tetapi dengan bantuan dokter dan alat media mereka tetap bisa hidup dan berjuang. Sampul novel "Five Feet Apart" sudah sesuai dengan prinsip-prinsip desain.

\section{DAFTAR PUSTAKA}

Agnes, T. (2019). Novel Roman 'Five Feet Apart' Terbit Diakses dari https://hot.detik.com/book/d-4468952/novel-roman-five-feet-apart-terbit-di-indonesia 19-maret pada tanggal 08 Mei 2020 pukul 22.30 WIB.

Hans, E. (penerjemah). (2010). Teori Desain Grafis. Yogyakarta: Penerbit ANDI.

Dayana, A. S. (2019). 5 Sinopsis Film "Five Feet Apart", Cinta yang Terpisah 5 Langkah. Dikutip dari https://tirto.id/sinopsis-film-five-feet-apart-cinta-yang-terpisah-5 langkahdj6c pada tanggal 08 Mei 2020 pukul 22.30 WIB.

Maharsi, I. (2016). Ilustrasi. Yogyakarta: Badan Penerbit ISI Yogyakarta.

Mahesa, Y. (2019). Mengenal Jenis-Jenis Font. Dikutip dari https://www.nawadwipa.co.id/ mengenal-jenis-jenis-font/pada tanggal 08 Mei 2020 pukul 22.30 WIB.

Moleong, L. J. (2007). Metodologi Penelitian Kualitatif. Bandung: PT. Remaja Rosdakarya Offset. 